\title{
Study on microstructural and mechanical properties of dissimilar joint of laser beam welded Inconel 625 and SS 316
}

\author{
Akshansh Mishra ${ }^{\# *}$, Devarrishi Dixit^ and Abhishek Kumar Sharma! \\ \#Department of Mechanical Engineering, SRM Institute of Science and Technology, Kattangulathur, India \\ ${ }^{\wedge}$ Department of Materials Science Engineering, UPES, Dehradun, India \\ !Department of Mechanical Engineering, Indraprastha Engineering College, Ghaziabad, India
}

Received 22 March 2018, Accepted 29 March 2018, Available online 30 March 2018, Vol.6, No.1 (March 2018)

\begin{abstract}
This paper investigates the microstructure and properties of deep penetrated laser welded dissimilar joints of Inconel 625 nickel based alloys and 316 Stainless Steel. Evaluation of weld microstructures through optical microscopy, Brinell Hardness test, Tensile test at room temperature and stress rupture properties were done. The Experimental results showed that the microstructure of the weld zone near the fusion line in Inconel 625 were columnar dendrites, whereas that near the fusion line in SS 316 were mainly cellular. The tensile strength tests indicated that the dissimilar butt joints ruptured in the fusion zone.
\end{abstract}

Keywords: Dissimilar Metals; Laser Beam Welding; Microstructure Properties; Mechanical Properties

\section{Introduction}

Inconel 625 alloy was initially designed as a solid solution hardened alloy. It is a wrought nickel based super alloy which is strengthened by the additions of niobium, carbon, chromium, molybdenum (V. Shankar et al, 2001). The main application of Inconel 625 are aircraft ducting systems, engine exhaust systems, thrust-reverser systems, resistance welded honeycomb structures for housing engine controls, fuel and hydraulic line tubing, spray bars, bellows, turbine shroud rings, and heat-exchanger tubing in environmental control systems. It is also suitable for combustion system transition liners, turbine seals, compressor vanes, and thrust-chamber tubing for rocket. Nowadays, it is used in high performance exhaust systems, the cutting edge of motorsport is perfect for this material due to its lightweight nature, how thin it can be fabricated and the temperatures it can handle. 316 Stainless Steel 316 is the standard molybdenum-bearing grade, second in importance to 304 amongst the austenitic stainless steels (J.K.L Lai et al, 1983). The molybdenum gives 316 better overall corrosion resistant properties than Grade 304, particularly higher resistance to pitting and crevice corrosion in chloride environments. It has excellent forming and welding characteristics. It is readily brake or roll formed into a variety of parts for applications in the industrial, architectural, and transportation fields. Grade 316 also has outstanding welding

*Corresponding author's ORCID ID: 0000-0003-4939-359X DOI: https://doi.org/10.14741/ijaie/v.6.1.2 characteristics. Post-weld annealing is not required when welding thin sections.

It is important to consider various factors before attempting to join two different metals, as this will determine not only how successful the welding will be, but also how long your newly joined components are likely to last. Firstly, the solubility that is the chemical properties of a substance which determines its ability to dissolve in a solvent, of the two dissimilar metals must be mutual. If the metals cannot be dissolved together, then the welding process will fail successfully welded without resulting in cracks or any other kind of negativity.

Laser welding is used more frequently in industrial processes because it has wider application than traditional welding as less heat is created because the beam is so focused. This means that heat transfer to the workpiece is much less and the metallurgical structure is less affected and the quality of the weld is much higher than with traditional forms of welding. Laser beam welding is highly preferable for joining dissimilar metals. So far, the microstructural and mechanical properties of dissimilar welded Inconel 625 and SS 316 by high power laser have been not studied.

In this paper, the dissimilar laser beam welded joints of Inconel 625 and 316 Stainless Steel were formed with one-pass fully penetrated weld using highpower $\mathrm{CO}_{2}$ laser. The microstructure of the weld metal including fusion boundary and element segregation was investigated, and the relationship between the microstructures and the tensile strength were evaluated. 
Table 1: Chemical composition of base metal by wt\%

\begin{tabular}{lccccccccccc}
\hline Materials & $\mathrm{Cr}$ & $\mathrm{Ni}$ & $\mathrm{C}$ & $\mathrm{S}$ & $\mathrm{Mn}$ & $\mathrm{Si}$ & $\mathrm{Mo}$ & $\mathrm{Nb}$ & $\mathrm{Ti}$ & $\mathrm{Al}$ & $\mathrm{Fe}$ \\
\hline SS 316 & 18.0 & 14.0 & 0.08 & 0.030 & 2.00 & 1.00 & 3.0 & - & - & - & $\mathrm{Bal}$ \\
Inconel 625 & 22.1 & $\mathrm{Bal}$. & 0.02 & 0.001 & 0.05 & 0.09 & 9.2 & 3.45 & 0.18 & 0.14 & 4.6 \\
\hline
\end{tabular}

Table 2: Parameters for laser welding processing of Inconel 625 and SS 316

\begin{tabular}{lcccccc}
\hline Parameters & Gas Type & Beam Diameter(mm) & Power(Watt) & Focus(mm) & Speed(mm/min) & Frequency(Hz) \\
\hline Weld Joint & Helium & 2 & 3200 & 16 & 1.5 & 20000 \\
\hline
\end{tabular}

\section{Experimental procedure}

Inconel 625 plate of dimensions $200 \mathrm{~mm} \mathrm{X} 75 \mathrm{~mm} \mathrm{X}$ $3 \mathrm{~mm}$ used in this research was supplied by Skyland Metals and alloys Inc., Mumbai. SS 316 is austenitic chromium-nickel stainless steel containing Molybdenum. The chemical composition of both the alloys is shown in Table 1.

Inconel 625 and SS 316 plates were machined in order to get smooth surface finish by removing oil remains and rust. There should be no gapping between the plates when they are brought against each other. After checking for the gapping, the both plates were mounted on the fixture as shown in the Fig.1. Using continuous wave $\mathrm{CO}_{2}$ laser equipment TLC 1005 dissimilar butt joints were obtained. The parameters used for laser welding both plates are listed in Table 2. The inert gas Helium was used as side blowing gas during the welding processing.

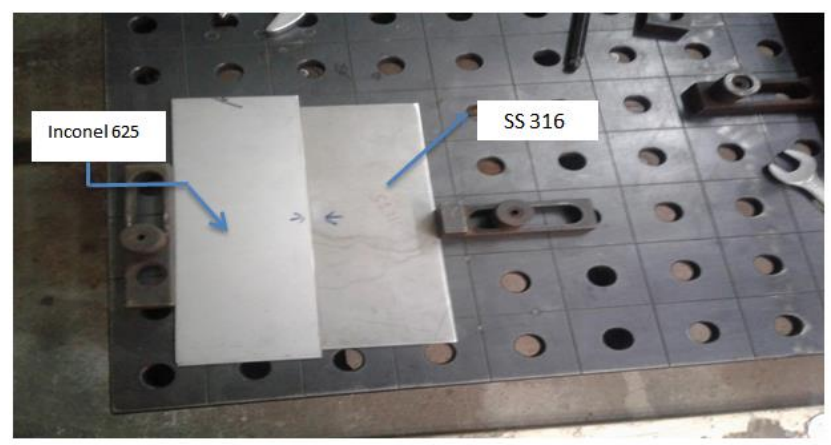

Fig.1: Fixture assembly for joining Inconel 625 and SS 316

Microstructure test was carried out after laser welding processing of dissimilar butt joints of Inconel 625 and SS 316. The specimens were polished using emery papers of grades 200, 400 and 1200. Etchant used was $50 \mathrm{ml} \mathrm{HCl} \mathrm{37 \% ,} \mathrm{20ml} \mathrm{HNO3} \mathrm{90 \% ,} \mathrm{10ml} \mathrm{H2SO4} \mathrm{97 \% .}$ Etch time was 10 seconds for SS 316, 20seconds for Inconel and 15 seconds for weld joint.

Brinell Hardness test was carried out at interval of $2 \mathrm{~mm}$ from the weld joint. During Brinell Hardness test, diameter of indenter was $2.5 \mathrm{~mm}$ and applied load was 187.5 kgf. Tensile test specimen of width $12.4 \mathrm{~mm}$, thickness $2.60 \mathrm{~mm}$ and area $32.2 \mathrm{~mm}^{2}$ was prepared as shown in Fig. 2.

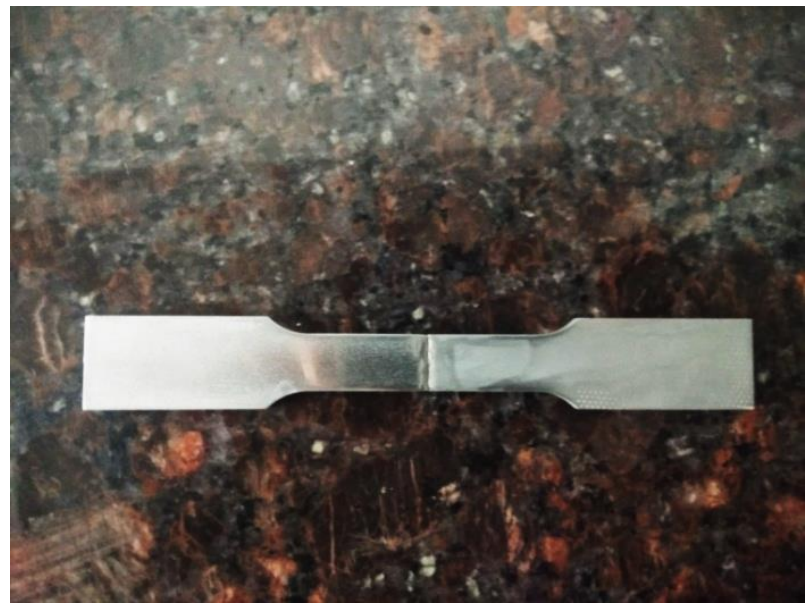

Fig. 2: Tensile test specimen of dissimilar joints

\section{Results and discussions}

\subsection{Weld Microstructure}

The main interest of study in dissimilar welded joints has always been focussed on the microstructure of fusion boundary. Melting of base metals and weld pool results element segregation.

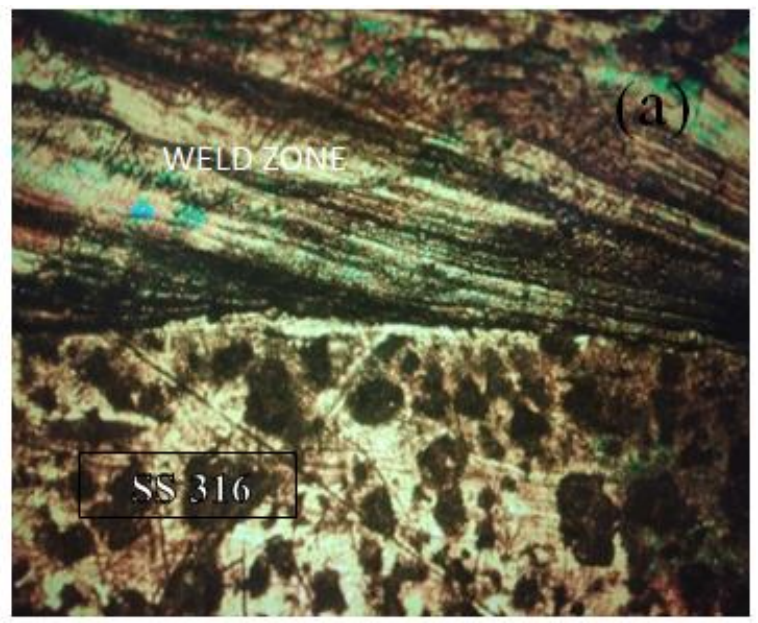




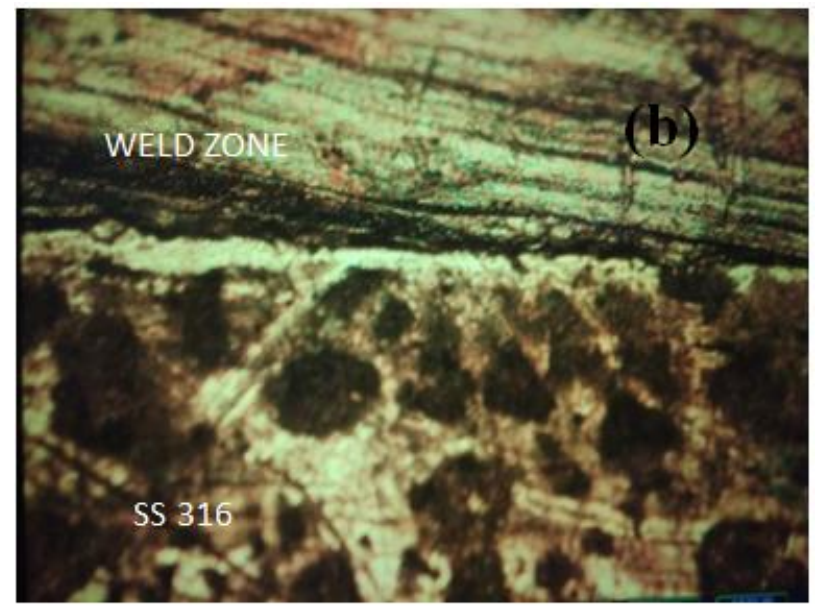

Fig. 3: Microstructure of weld zone and SS 316. a) Magnification is $5 \mathrm{X}$. b) Magnification is $10 \mathrm{X}$
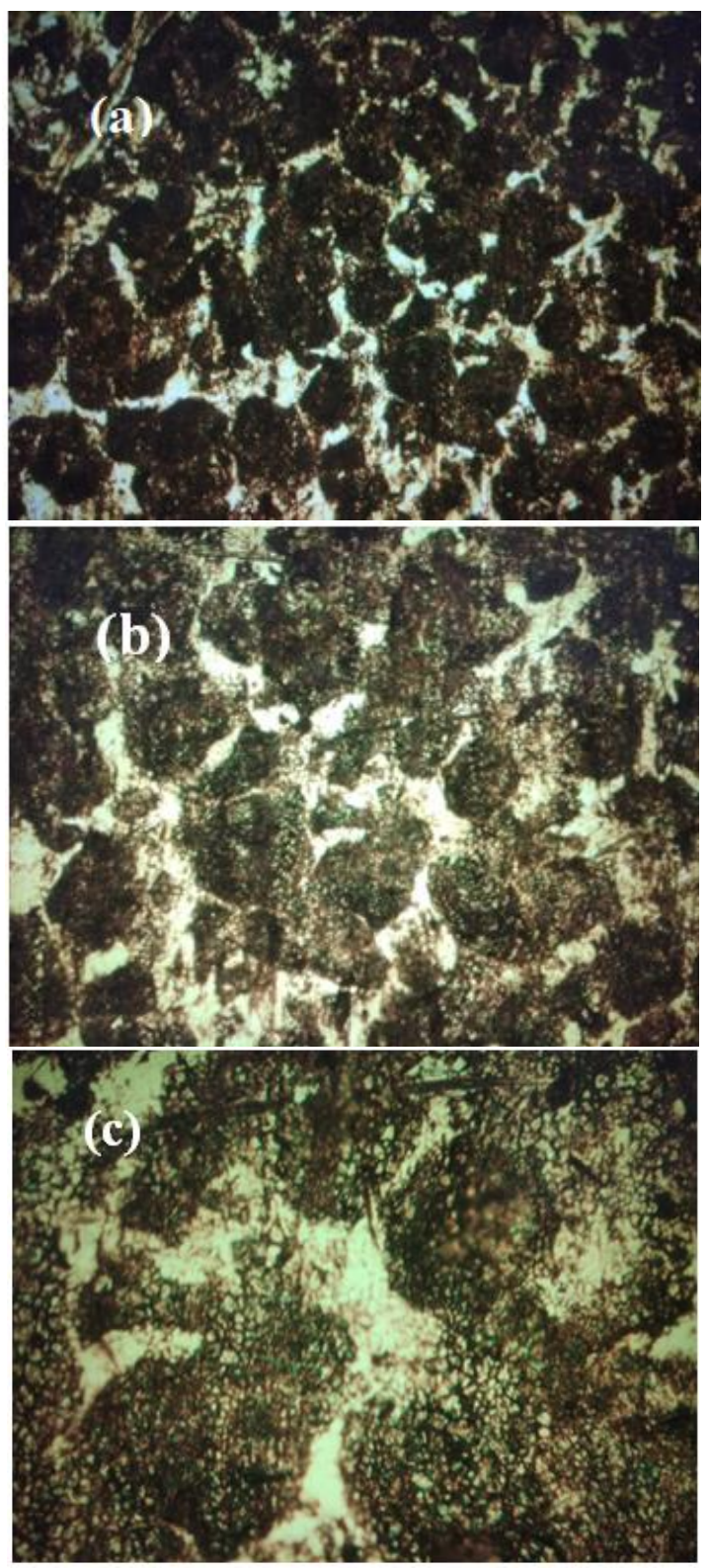

Fig. 4: Microstructure of SS 316 near Weld zone at Magnification of a) 10X, b) 20X and c) 50X
Fig. 3 represents the meeting point of SS 316 (bottom) and the weld zone (top). From the Fig. 4, we can easily observe that the microstructure of the weld zone near the fusion line of SS 316 is cellular in nature.
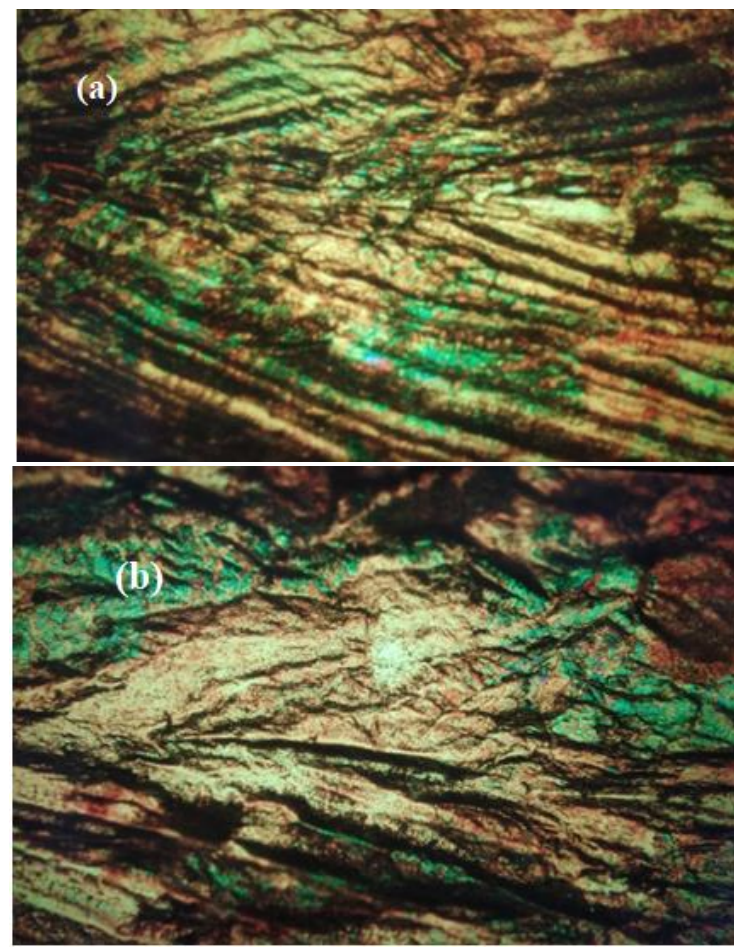

Fig.5: Microstructure of Weld Zone at Magnification of a) $10 \mathrm{X}$ and b) $50 \mathrm{X}$
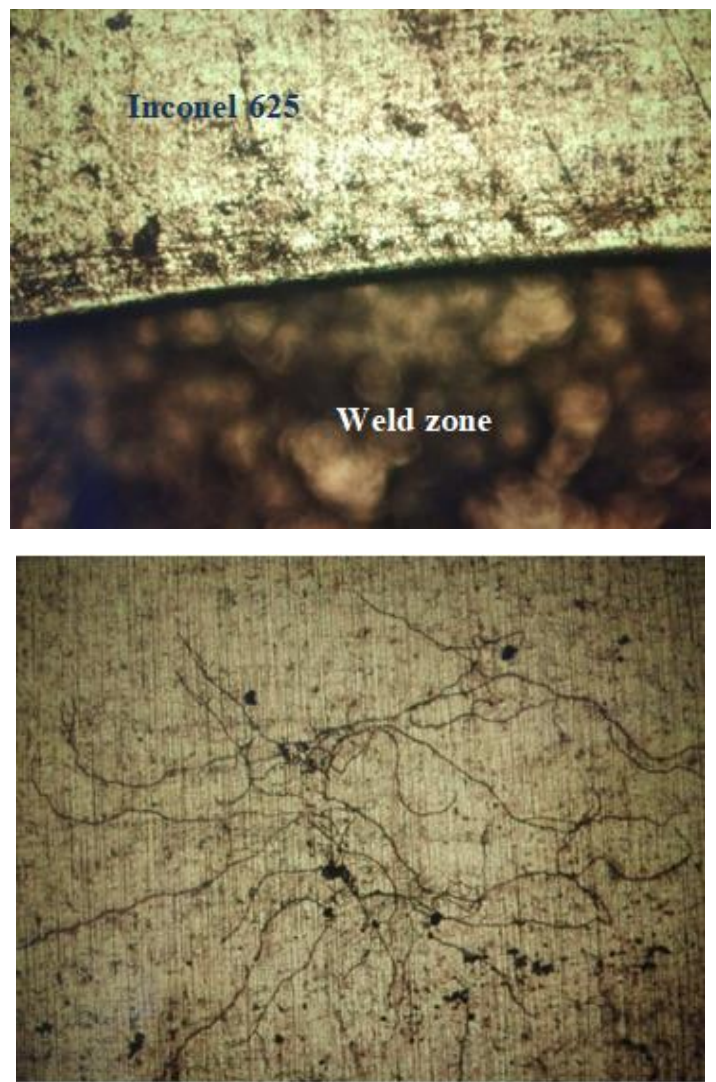

Fig.6: Microstructure of Inconel 625 near weld zone 
From Fig. 5 it is observed that at the weld zone formation of splined intermetallic compounds takes place. It can be observed from Fig. 6 that the microstructure of the weld zone near the fusion line of Inconel 625 was columnar dendrites. From the various case studies it is known that in the fusion zone of nickel based alloys with high contents of $\mathrm{Nb}$ and Mo, laves phase are precipitated. Laves phase are formed in inter dendritic regions of the weld metals as a result of segregation (GDJ Ram et al, 2005; Çam G et al, 1998; Gobbi S et al, 1996). The composition and morphological properties of laves phase strongly depends on heat input and cooling rate.

It can be further observed that there is non-uniform distribution of very fine particles at the grain boundary of cellular region, while the coarse and long chain particles were in the dendritic regions of fusion zone.

\subsection{Tensile Test}

In order to know more about the nature of weld, Tensile test was performed as shown in the Fig. 7. Complete tensile profile is obtained when the dissimilar welded specimen is continued to pull until it ruptures as shown in the Fig.8. Tensile test is usually carried out to measure the elongation, tensile strength and reduction in area of the base metals and weld metals. By averaging the four sets of data for specimens, the result of Tensile test was obtained as shown in the Table 3.

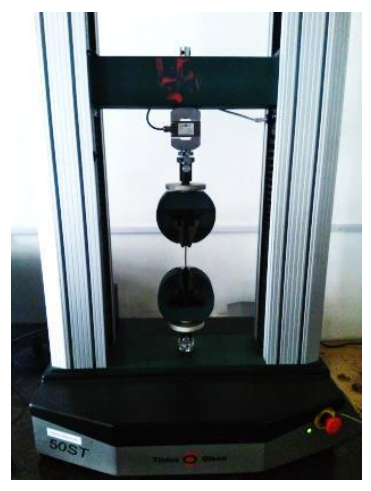

Fig.7: Tensile Testing of Dissimilar welded specimen

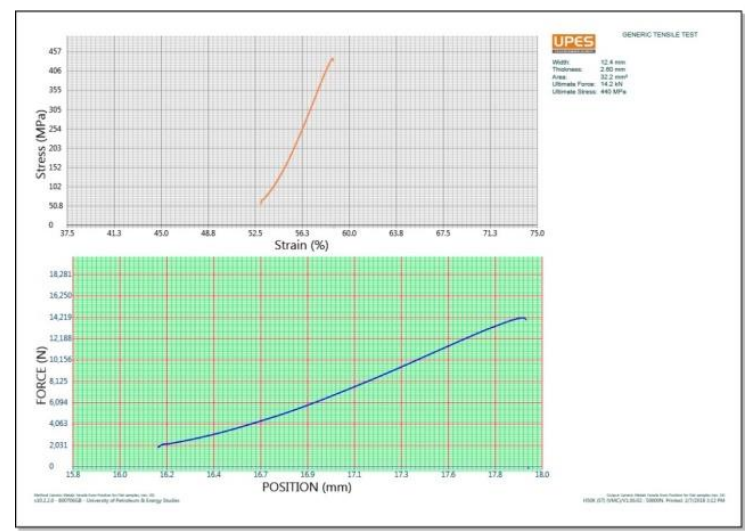

Fig. 8: Tensile test profile of the dissimilar welded specimen
Table 3: Results for Tensile Test at room temperature

\begin{tabular}{lccc}
\hline Specimen & Elongation (\%) & Tensile Strength (Mpa) & Reduction in area (\%) \\
\hline Inconel 625 & 42.26 & 875.6 & 27.86 \\
SS 316 & 41.91 & 784.5 & 54.32 \\
Weld Joint & 24.42 & 440 & 25.21 \\
\hline
\end{tabular}

From the Table 4, it is concluded that the tensile strength value of weld metal was $440 \mathrm{Mpa}$ which is weaker than that of base metals. The dissimilar weld joint of Inconel 625 and SS 316 was ruptured along the fusion line between Inconel 625 and weld metal in shear fracture mode.

\subsection{Hardness}

The Brinell Hardness Test results are shown in Fig. 9. An upward trend in hardness is observed across the welds of SS316 and Inconel 625. The reason for increase in hardness is due to presence of $\mathrm{Nb}$ rich and Mo rich precipitate in inter dendritic region.

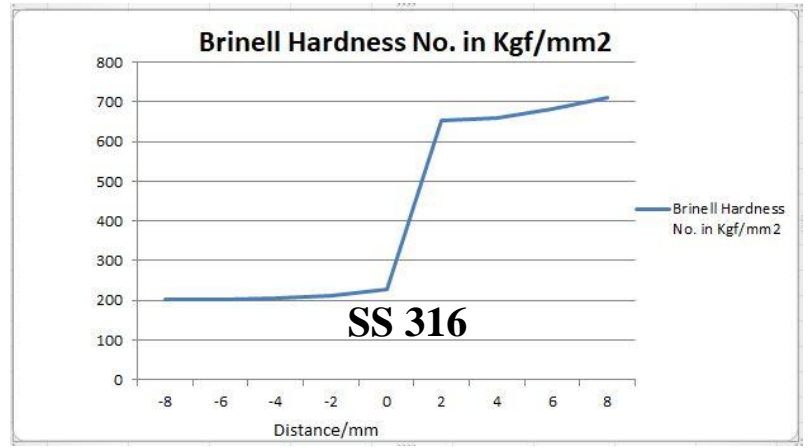

Fig. 9: Brinell Hardness profile on transverse cross section of weld

\section{Conclusions}

The microstructure of the dissimilar butt joints of Inconel 625 and SS316 stainless steel was evaluated. It was observed that the microstructure of weld zone near the fusion line in Inconel 625 was predominantly long columnar dendrites, whereas that near the SS316 was cellular in nature. The tensile strength of the dissimilar joints declined sharply compared to the base metals. The Brinell Hardness test showed uptrend increase in Hardness value from SS316 to Inconel 625 across the weld joint.

\section{References}

Shankar, V., Rao, K.B.S. and Mannan, S.L., (2001). Microstructure and mechanical properties of Inconel 625 superalloy. Journal of Nuclear Materials, 288(2-3), pp.222-232.

Lai, J.K.L., (1983). A review of precipitation behaviour in AISI type 316 stainless steel. Materials Science and Engineering, 61(2), pp.101-109.

Ram GDJ,Reddy AV, Rao KP,Reddy GM(2005).Microstructure and mechanical properties of Inconel 718 electron beam welds. Materials Science and Technology 21: pp. 1132-1138.

Cam G, Koçak M (1998). Progress in joining of advanced materials part II: joining of metal matrix composites and joining of other advanced materials. Science and Technology of Weld Join 3: pp. 159-175.

Gobbi S, Zhang L, Norris J, Richter KH, Loreau JH (1996). High powder CO2 and Nd-YAG laser welding of wrought Inconel 718. J Materials Processing Technology 56: pp.333-345 